\title{
Jovem empreendedor no Brasil: a busca do espaço da realização ou a fuga da exclusão?*
}

\author{
Yára Lúcia M. Bulgacov** \\ Sieglinde Kindl da Cunha*** \\ Denise de Camargo**** \\ Maria Lucia Meza***** \\ Sergio Bulgacov*******
}

\begin{abstract}
Sumário: 1. Introdução; 2. Concepção e contextualização da atividade empreendedora; 3. Atividade empreendedora do jovem; 4. Políticas públicas: orientações estratégicas para o jovem empreendedor; 5 . Considerações finais.
\end{abstract}

Summary: 1. Introduction; 2. Concept and context of entrepreneurial activity; 3. Young entrepreneurial activity; 4. Public policies: strategic guidelines for young entrepreneurs; 5. Final considerations.

Palavras-chave: jovem empreendedor; trabalho precário; empreendedor por necessidade; empreendedor por oportunidade.

\footnotetext{
* Artigo recebido em dez. 2009 e aceito em jun. 2010

** Doutora em educação pela Universidade Estadual Paulista (Unesp, Campus Marília). Professora titular do mestrado e doutorado em administração da Universidade Positivo. Professora e pesquisadora sênior da Universidade Federal do Paraná (UFPR). Endereço: Rua José F. Dalledone, 105, casa 6 - São Lourenço - CEP 82200-164, Curitiba, PR, Brasil. E-mail: ybulgacov@gmail.com. $* * *$ Doutora em economia pela Universidade Estadual de Campinas (Unicamp). Professora e pesquisadora do mestrado e doutorado em administração da Universidade Positivo. Professora e pesquisadora sênior da UFPR. Endereço: Rua Rui Arzua Pereira, 64 - Abranches - CEP 82130190, Curitiba, PR, Brasil. E-mail: skcunha21@gmail.com.

**** Doutora em psicologia social pela Pontifícia Universidade Católica de São Paulo (PUC-SP). Professora titular da Universidade Tuiuti do Paraná. Professora aposentada da UFPR. Endereço: Rua Raposo Tavares, 5332 - CEP 82100-000, Curitiba, PR, Brasil. E-mail: denisedecamargo@ uol.com.br.

***** Doutora em Desenvolvimento Econômico pela UFPR. Professora e pesquisadora do Mestrado em Administração Pública da Universidade Tecnológica do Paraná (UTF-PR). Endereço: Rua Boleslau Kuroski, 102 - CEP 81200-190, Curitiba, PR, Brasil. E-mail: malumeza2@unicenp.edu.br. ******* Doutor em administração pela Fundação Getulio Vargas de São Paulo (GFV-SP). Professor e pesquisador da FGV-SP. Endereço: Rua José Francisco Dalledone, 105, casa 6 - São Lourenço — CEP 82200-164, Curitiba, PR, Brasil. E-mail: s.bulgacov@ufpr.com.
} 
KEY WORDS: young entrepreneur; precarious labor; entrepreneur by necessity; entrepreneur by opportunity.

Este artigo focaliza a trajetória do jovem brasileiro (18-24 anos) no empreendedorismo no período de 2001-08. Com base em dados da Pesquisa GEM, analisa-se a participação do jovem empreendedor da América Latina e do Bris (Brasil, Rússia, Índia e África do Sul). Priorizam-se as atividades empreendedoras iniciais do jovem, sua motivação (empreender por necessidade ou oportunidade), características de renda, escolaridade, tipo de atividade e políticas públicas. Associando métodos quantitativos e qualitativos, descreve-se o perfil da atividade empreendedora do jovem brasileiro contextualizando-a a partir de fontes secundárias como o IBGE, BID, PNAD, OIT e OMS. Observou-se que no Brasil a maior parte dos jovens são autoempregadores, empregam poucas pessoas em seus negócios e com pouca estrutura para enfrentamento de riscos. Baixo índice de escolaridade, entre outros fatores, encaminham o negócio no sentido de uma probabilidade maior de fracasso. Empreendimentos que sobrevivem não resultam em impactos econômicos, mantendo de forma precária a sobrevivência de um grande número de jovens, excluídos do mercado de trabalho formal. Por outro lado, os jovens que empreendem por oportunidade são um grupo relativamente pequeno. Eles identificam oportunidades e têm melhores habilidades para sustentá-las. Por fim, destaca-se que o apoio e a sustentabilidade do jovem empreendedor dependem do contexto geral e de políticas educacionais.

\section{Young entrepreneurs in Brazil: the search of room for achievement or an escape} from exclusion?

This article focuses on the path of young (18-24 year old) Brazilian entrepreneurs during the period 2001 and 2008. Based on data from the GEM Study, we analyzed young peoples' participation in entrepreneurship within Latin American and Bris countries (Brazil, Russia, India, and South Africa). Toward the goal of uncovering peculiarities of this entrepreneurial segment, we focus only on the youths' initial entrepreneurial activities, their motivation (entrepreneurship by necessity or opportunity), revenue, education, activity sector as well as on policies and support mechanisms. Associates quantitative and qualitative methods, and contextualized with secondary sources such as IBGE, BID, PNAD, OIT, and OMS. It was found that, in Brazil, the majority of youths are self-employed, have few employees in their businesses and dispose of few resources to face risk. Factors such as low levels of education and other factors, among others, tend to push their businesses toward a higher probability of failure. Businesses that survive do not yield significant economic impacts, but rather merely maintain the precarious survival of a great number of youths that are excluded from the formal labor market. On the other hand, young people who are entrepreneurs "by opportunity" are part of a relatively small group and are able to support them. Finally, we emphasize that support and sustainability of young entrepreneurs depend on the context and public policy. 


\section{Introdução}

O interesse em refletir sobre a participação do jovem brasileiro no empreendedorismo se dá por vários motivos. "Primeiro, por ser, o Brasil, do ponto de vista demográfico, um país jovem e ser a juventude uma etapa de transição que processa a passagem de uma condição social mais recolhida e dependente a uma mais ampla; um período de preparação para o ingresso na vida adulta" (Unesco apud Waiselfisz, 1998:154). Segundo, pelo aumento que se tem observado na participação do jovem brasileiro no empreendedorismo. Pela primeira vez em nove anos, a participação do jovem empreendedor alcança e supera os demais segmentos etários analisados (Global Entrepreneurship Monitor, 2008). É uma geração de jovens ingressando no mercado de trabalho via empreendedorismo e que precisa ser analisada detalhadamente para se compreender as características e condições dessa atividade empreendedora revelada pelos números da pesquisa. Carreteiro (2001) traz o "conceito de projeto" ao constatar que o ser humano vive em constante movimento para a transcendência e de identificação com o esforço de ultrapassagem contínua. No projeto, está contido o vir a ser, a transcendência, a direção para o futuro, a afirmação do homem pela ação; é o projeto um dos organizadores da existência. Nesse sentido, é o projeto profissional uma das dimensões centrais da juventude, quando o jovem projeta seu vir a ser profissional. Há projetos, afirma, marcados pela tendência à autonomia, em cuja construção domina a inovação/criação; sendo outros projetos apenas reprodução. Assim, a própria atividade empreendedora, a depender das características e das condições, pode, por um lado, garantir realização, por outro, vulnerabilidade.

Pergunta-se: quem é esse jovem que empreende? Qual sua escolaridade? Em que setor de atividade o jovem concentra seu empreendimento? Os jovens empreendem por necessidade ou por oportunidade? Qual a renda que esses jovens conseguem atingir? Como tem se apresentado a tendência da atividade empreendedora no período de 2001 a 2008? Na atual conjuntura brasileira, o que justifica o crescimento da participação do jovem no empreendedorismo? E, finalmente, pode-se falar de jovens empreendedores como um grupo único, ou os dados da pesquisa GEM mostram grupos diferentes de jovens desenvolvendo atividades empreendedoras?

O artigo está dividido em cinco seções, incluindo esta introdução. A seção 2 introduz o conceito e a contextualização da atividade empreendedora que serão utilizados nesse trabalho. Na seção 3 desenvolve-se a caracterização propriamente dita do perfil do jovem empreendedor; na sequência, o quarto 
tópico sugere orientações estratégicas para o jovem a partir de políticas pública e, por último, as considerações finais.

\section{Concepção e contextualização da atividade empreendedora}

Neste trabalho opta-se por conceituações mais descritivas dos termos que envolvem o campo do empreendedorismo. Contestam-se concepções individualizantes do fenômeno do empreendedorismo, como, por exemplo, a de McClelland (1972), que buscava um fator psicológico, a "necessidade de realização" ( $n$ realização), como o fator responsável pelo comportamento empreendedor e, consequentemente, pelo desenvolvimento econômico. O projeto de McClelland foi entender como o fator $n$ realização explicava as diferenças individuais que constituíam o homem ativo, o homem realizador, aquele homem que se esforça sistematicamente para superar metas individuais internamente dirigidas. Concebia o empreendedor como portador de característica estável de personalidade, de um atributo, que influenciava atitudes e reações levando ao empreendedorismo; portanto, uma abordagem de traços de personalidade, uma abordagem centrada no indivíduo. Assim, a psicologia de McClelland é uma psicologia individual, com tendência a entender que os processos psicológicos são produzidos no indivíduo. Uma concepção psicológica que, ao assumir uma representação social do indivíduo como um agente autônomo e único responsável por seu sucesso ou seu fracasso, oculta o jogo de interesses e valores sempre presentes na construção do conhecimento. Uma concepção que tem suas raízes no individualismo, baseado na tradição intelectual do Ocidente; uma concepção que naturaliza o fenômeno psicológico, perdendo de vista que esses valores são produtos culturais de uma sociedade e que conceitos e teorias são produtos culturais socialmente construídos e legitimados, assim favorecendo a despolitização da disciplina (Camargo, Cunha e Bulgacov, 2008).

Refuta-se igualmente para a análise do jovem empreendedor a concepção behaviorista, orientada pela categoria de "comportamento", na medida em que concebe o homem como reativo, influenciado pelo meio externo, encapsulado em um modelo reducionista e determinista externo. Contrapondose a essa concepção, adota-se uma concepção sócio-histórica e cultural da atividade empreendedora, que em momento algum dissolve o sujeito empreendedor em perspectivas socializantes. Adota-se o conceito de atividade, tão importante para a psicologia sócio-histórica quanto o conceito de comportamento para o condutivismo. Supera-se o modelo explicativo S_R (EstímuloResposta), concepção em que o ambiente é responsável pelo comportamento 
humano, adotando-se "sujeito-atividade-objeto", que pressupõe um sujeito e uma intencionalidade voltada ao objeto, imersos num ambiente cultural, histórico, essencialmente significativo para o homem. A atividade empreendedora será compreendida como uma atividade dirigida por um sujeito, situado e enraizado no social, onde o indivíduo, embora não se subordine às condições, delas não se separa. Explica Clott (2006) que a atividade é sempre dirigida por um sujeito, um sujeito sempre em relação com outro e com o objetivo, mediados pela cultura, reafirmando a inseparabilidade do contexto.

Pochmann (2009:2), pincelando o cenário do segmento jovem no Brasil atual, afirma:

No Brasil temos 37 milhões de jovens na faixa etária de 16 a 24 anos. A metade desses jovens não estuda. A outra metade que estuda está fora de série, não acompanha a relação idade e série. Os jovens filhos de pobres no Brasil só estudam quando trabalham. Nós não temos estudantes que trabalham, mas jovens trabalhadores que estudam. Quando falta trabalho ou a renda é pouca ele abandona o estudo. Este ano 500 mil jovens do ensino médio abandonarão a escola por não ter complementação de renda. Um jovem que trabalha e estuda está comprometendo 16 horas diárias, ou seja, não tem tempo pra estudar.

Em que condições, portanto, esse jovem está empreendendo? Estará esse empreendimento "ocupando" suas horas de dedicação à sua formação? Qual a escolaridade desse jovem que lhe permitiria condições de competitividade no setor que empreende? Que condições de empreendimento são essas? Que atividade empreendedora é essa, situando-a no contexto econômico maior?

Holzman (2006:84), ao fazer uma análise das estatísticas do IBGE/ Pnad, afirma que o trabalhador por conta própria, ou o pequeno empreendedor por necessidade, "constitui o personagem-símbolo do ideário neoliberal, o qual, na apologia das vantagens que usufrui, encobre a precariedade que, em geral, o caracteriza". O trabalho por conta própria, ou o empreendedorismo por necessidade, constitui-se, então, em "desaguadouro" do desemprego, e 78,3\% destes trabalhadores não são contribuintes da previdência social (Holzman, 2006:84). Assim, pode-se inferir que a atividade empreendedora, particularmente quando decorre de uma ação realizada por necessidade de sobrevivência, é fruto dessas transformações conjunturais ocorridas nas relações de trabalho e emprego.

Até que ponto a denominada atividade empreendedora do jovem estaria associada à precarização das condições de trabalho, ao aumento do caráter precário das relações de trabalho, pela ampliação do trabalho profissional 
assalariado sem carteira e do trabalho independente, e aquele por conta própria? Até que ponto essa precariedade da atividade empreendedora jovem está mais significando uma alternativa precária à exclusão do que propriamente um meio de realização profissional inovadora e competente?

De acordo com Cattani e Holzmann (2006:203), a definição de trabalho precário contempla pelo menos duas dimensões: "a ausência ou redução de direitos e garantias do trabalho e a qualidade no exercício da atividade". Na primeira, considera-se o retrocesso em relação às conquistas trabalhistas constitucionais e negociações sindicais; e, na segunda, considera-se a relação entre ganhos e quantidade de trabalho e, complementarmente, aspectos ligados diretamente ao exercício da atividade. A precarização do trabalho se revela como uma sequência de perdas, como: redução da perspectiva profissional (contratos temporários, flexibilidade de demissões) e supressão de direitos (como descanso remunerado, férias, licenças de saúde, aposentadoria e regulação dos salários, entre outros). Essa realidade também é enfrentada por diversos tipos de trabalhadores, a exemplo de autônomos, ambulantes, artistas e os que desenvolvem atividades nas feiras.

Um processo que atinge todos os trabalhadores, independentemente de seu estatuto, e que tem levado a uma crescente degradação das condições de trabalho, da saúde (e da vida) dos trabalhadores e da vitalidade da ação sindical (Thébaud-Mony e Druck, 2007). Assim, a insegurança no emprego e sua precarização são causas da vulnerabilidade social, da perda de vínculos e referências de inserção, ou de "lugares" (Castells, 1999).

É necessário deixar claro que o trabalho autônomo, avulso e eventual e a atividade empreendedora não são emprego, nem são assalariamento. O que diferencia emprego e trabalho é o contrato. Todavia, há contratos que estabelecem relações de trabalho que não são relações de emprego, como ocorre nos casos do trabalho autônomo e por conta própria.

Uma das alternativas para o desemprego é o trabalho por conta própria, que, segundo definição do IBGE/Pnad (2006), é composto pela categoria de trabalhadores que exploram o próprio empreendimento, sozinhos ou com um sócio, sem empregar auxiliar assalariado. "É o pequeno empreendedor, o trabalhador patrão de si mesmo, dono do seu tempo e do seu ritmo de trabalho".

Em relação ao jovem empreendedor na América Latina, Llisterri (2006) chama a atenção para a questão: é o empreendedorismo jovem na América Latina um empreendedor por necessidade ou oportunidade? Salienta a necessidade de procura de novos modelos de encorajamento do empreendedorismo jovem diante de problemas como falta de experiência, recursos e escolarização, que levam à redução das taxas de sucesso do empreendimento. 
Faz-se aqui um paralelo do jovem empreendedor por necessidade e por oportunidade com uma distinção formulada por Guerreiro-Ramos (1989) entre comportamento e ação. Para o teórico, o comportamento é aquele que é socialmente condicionado à mercê de eventos episódicos, ficando à mercê de necessidades e contingência; motivado por conveniência/necessidade. Para fins de comparação, corresponderia ao que se está chamando de comportamento empreendedor motivado por necessidade. Em contrapartida, propõe o autor o termo ação, que pressupõe escolha, consciência, reflexão e proação, correspondendo ao comportamento do empreendedor jovem motivado.

Entende-se que, quando se analisa o perfil do empreendedor junto ao público jovem, a aprendizagem é elemento fundamental. Muitas pesquisas, entre elas a de Kristiansen e Indarti (2004), demonstraram que compreender a intenção empreendedora no jovem demanda identificar as características do entorno onde este jovem vive, que afetam favoravelmente a intenção empreendedora. E, neste caso, a aprendizagem se torna elemento indispensável, pois é a partir desse processo experimental que os jovens amadurecem e percebem suas habilidades, conhecimentos e motivação para empreender.

Do ponto de vista da aprendizagem, fazem uma aproximação da atividade do empreender com o processo de aprendizado descrito por Engeström (2004) e Wengler e Lane (2004), entendendo que, por meio de práticas de participação, negociação, experiência cumulativa, geram-se perturbação e descontinuidade, e novos significados são construídos. A atividade de empreender é experimental e fundamentalmente social, realinhando as experiências em relação ao contexto, transformando-o e sendo transformado por ele. Empreender é visto como um processo de aprendizagem que, através da prática, transforma as identidades e as habilidades dos indivíduos para participar do mundo, para mudar tudo ou alguma coisa, para mudar a si próprios. A ação empreendedora constitui trajetória de participação, ou seja, constitui histórias pessoais na relação com a história das comunidades, conectando o passado ao futuro, num processo tanto individual como coletivo.

\section{Atividade empreendedora do jovem}

Nesta seção procura-se revelar a atividade empreendedora do jovem brasileiro à luz de informações obtidas na Pesquisa GEM 2008 (Greco et al., 
2009) e no Projeto Cepal/Pnud/OIT (2008), buscando explicitar as interações sociais da atividade empreendedora do jovem dentro e fora do mundo do trabalho. Inicialmente será feito um mapa das tendências da atividade empreendedora no ranking mundial, comparando as características demográficas do jovem empreendedor no Brasil em relação a alguns países da América Latina e países do Bris (Brasil, Rússia, Índia e África do Sul). Em seguida, utilizando-se de dados da Cepal, Pnud/OIT, analisa-se o trabalho do jovem no Brasil, observando as tendências recentes a que está sujeito o jovem ao iniciar sua atividade no mundo do trabalho, que em grande parte são impostas pelas próprias condições socioeconômicas do desenvolvimento recente do Brasil. Por fim, elabora-se uma tipologia da atividade empreendedora do jovem brasileiro, utilizando-se de indicadores de formação, renda e setor de atividade do empreendimento, com informações da pesquisa GEM 2008.

\subsection{0 jovem no mapa do empreendedorismo da América Latina e países do Bris}

No decorrer do período 2001-08, a taxa de empreendedores iniciais (TEA) do Brasil manteve-se em torno de $13 \%$. No ranking dos países pesquisados pelo GEM, o Brasil encontrava-se na $12^{2}$ posição em 2008. No entanto, as tendências demográficas, considerados homens, mulheres, jovens e idosos, têm mudado no que concerne à atividade empreendedora. Um quarto da população brasileira de jovens entre 18 e 24 anos denomina-se como empreendedora; é a maior entre os países selecionados da América Latina e do Bris (gráfico 1). Entre 42 países que participaram da pesquisa GEM em 2008, o empreendedorismo jovem coloca-se na terceira posição no ranking mundial (25\%), sendo superado somente pelo Irã (29\%) e pela Jamaica (28\%).

Um dos achados da pesquisa GEM é a diferença entre a taxa de empreendedorismo dos jovens nos países desenvolvidos e nos não desenvolvidos. Os países mais desenvolvidos apresentam menores taxas de participação dos jovens empreendedores quando comparados com os países menos desenvolvidos; essa mesma relação é encontrada em outras pesquisas, quando se compara a inserção do jovem no mundo do trabalho em países de diferentes níveis de desenvolvimento (gráfico 2). 


\section{Gráfico 1}

Empreendedores iniciais em países da América Latina e Bris por faixa etária em 2008

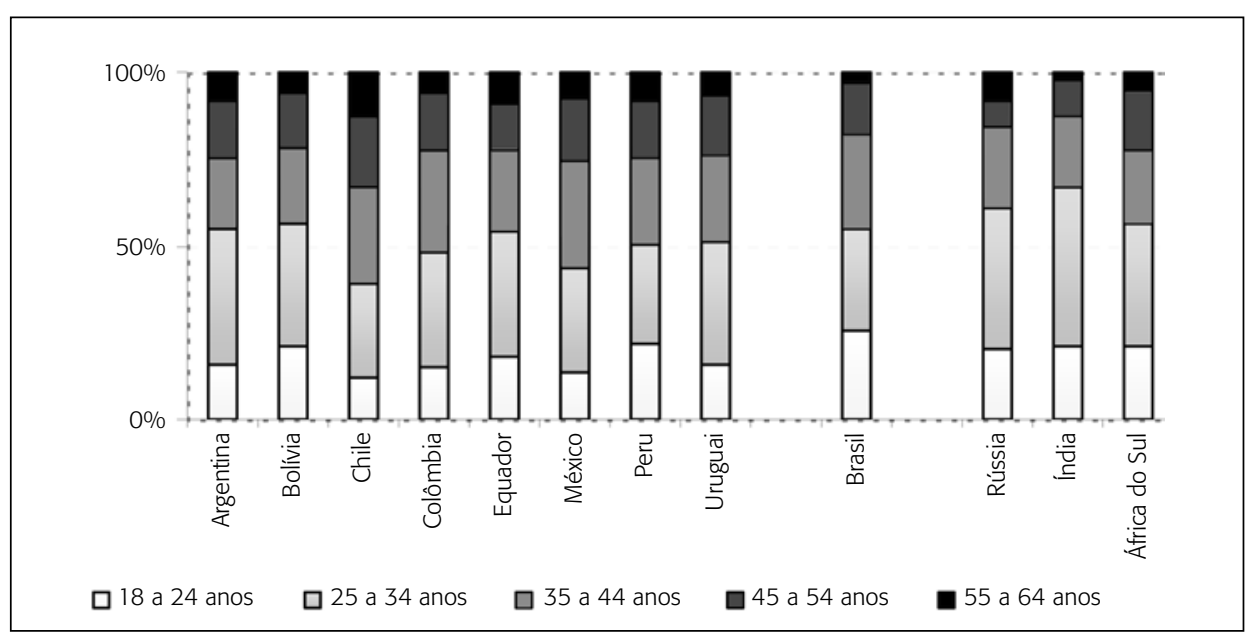

Fonte: Greco e colaboradores (2009).

Gráfico 2

Taxa de empreendedorismo do jovem entre 18 e 24 anos por países selecionados (2004)

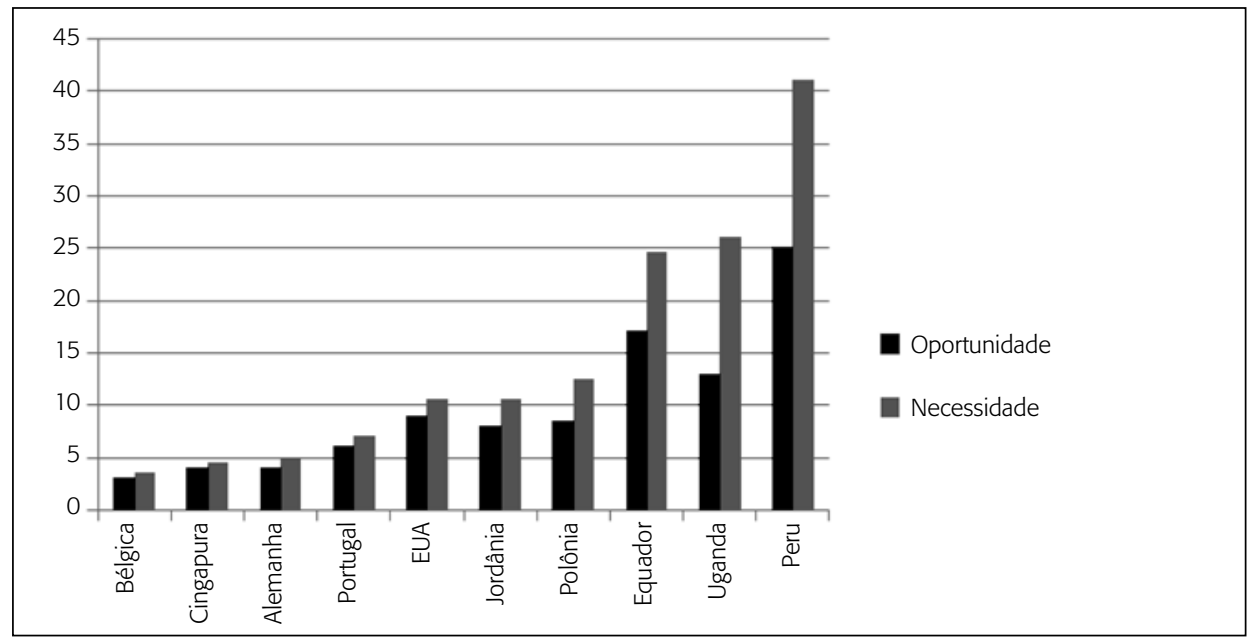

Fonte: Greco e colaboradores (2009). 
A análise dos fatores que levam esses países a apresentarem pouca atividade empreendedora entre jovens contribui para a compreensão dos fatores que levam os jovens brasileiros a encontrarem no empreendedorismo uma alternativa de emprego e renda, embora com fortes nuances de trabalho precário. Países com elevado nível de renda, estrutura de produção estável e padrão tecnológico elevado têm como diretrizes de política aumentar o tempo de formação e retardar a entrada dos jovens no mercado de trabalho.

Em contraposição, em países da América Latina, do Bris e em outros países pobres, o jovem é obrigado a entrar cedo no mercado de trabalho para garantir sua sobrevivência e/ou sua formação. Nesses países, o jovem empreendedor tem como única alternativa o trabalho, ou seja, uma atividade que assume por necessidade, como será observado em seguida. Esse jovem vai "empreender" com pouca formação e experiência, baixo nível de renda, situando-se em atividades de baixa produtividade, atividades de prestação de serviços, em busca de uma renda que, na maioria das vezes, não lhe permite uma sobrevivência digna e prejudica sua formação.

\subsection{A situação da juventude brasileira em relação ao trabalho}

Os dados da Cepal/Pnud/OIT (2008) mostram o panorama da situação da juventude no Brasil. Como pode ser visto na tabela 1, a participação do jovem brasileiro de 16 a 24 anos no total da ocupação cai, de 1992 a 2006, de 26\% para 23\%. Essa retração decorre, entre outros fatores, da mudança na pirâmide etária brasileira, que demonstra tendência crescente de envelhecimento da população, decorrente de menores taxas de fecundidade e maior expectativa de vida da população.

Tabela 1

Participação dos jovens de 16 a 24 anos no mercado de trabalho e no estudo (Brasil, 1992 e 2006)

\begin{tabular}{|lcc|}
\hline \multicolumn{1}{|c|}{ INDICADORES } & \multicolumn{2}{c|}{ PARTICIPAÇÃO \% } \\
\cline { 2 - 3 } & 1992 & 2006 \\
\hline Na população de 16 anos ou mais & 26,3 & 23,1 \\
Na população economicamente ativa de 16 anos ou mais & 26,5 & 22,4 \\
No total de ocupados de 16 anos ou mais & 25,0 & 20,1 \\
Taxa de participação dos jovens (PEA/PIA) de 16 a 24 anos & 69,7 & 67,9 \\
Jovens estudantes em \% do total de jovens de 16 a 24 anos & 30,7 & 42,3 \\
\hline
\end{tabular}

Fonte: Projeto..., 2008. 
Outro indicador que identifica o jovem no mercado de trabalho é que sua participação no total dos ocupados no período de 1992 e 2006 (25\% para 20,1\%) tem caído mais do que no total da População Economicamente Ativa (PEA) (69,7\% para 67,9\%). Essa diferença nas taxas é um forte indício de que os jovens estão enfrentando um cenário de maior dificuldade de inserção no mercado de trabalho. O diagnóstico de que piorou a inserção dos jovens no mercado confirma-se pela variação das taxas de desemprego (gráfico 3).

O gráfico 3 mostra que a taxa de desemprego entre jovens no Brasil é 3,2 vezes superior à registrada entre adultos: enquanto a taxa de desemprego das pessoas com 25 anos ou mais subiu de 4,3\% para 5,6\% (uma alta de 32\%), a dos jovens cresceu de $11,7 \%$ para $18 \%$ (uma alta de $53 \%$ ).

\section{Gráfico 3}

Taxa de desemprego de jovens e adultos no Brasil (1992 a 2006)

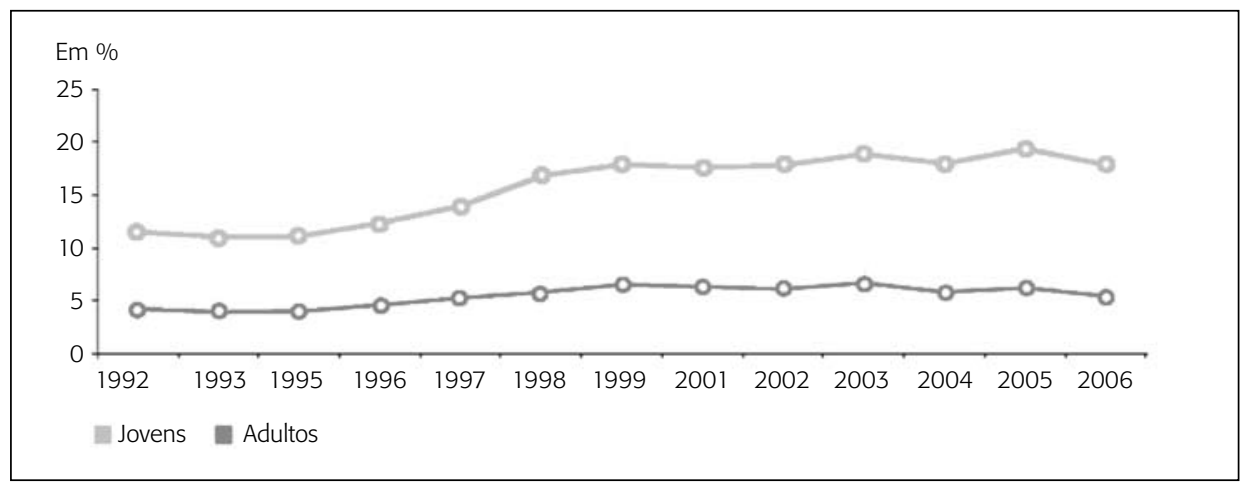

Fonte: Projeto..., 2008

Ao mesmo tempo, a informalidade é mais elevada entre os jovens, ou seja, eles têm mais dificuldade de ingressar no mercado de trabalho; e quando encontram algum tipo de atividade, essa se caracteriza como um trabalho precário.

Além da maior incidência de desemprego entre os jovens, os dados da tabela 2 mostram que 59\% dos jovens profissionais da faixa etária entre 16 e 24 anos não têm carteira de trabalho assinada. A informalidade entre a mão de obra jovem (59\%) é superior à registrada entre os adultos (51\%). De acordo com o estudo, a maior frequência de emprego sem carteira assinada entre os jovens se deve ao fato de a maior parte estar empregada em micro e pequenas empresas, onde é maior a parcela de informalidade. Também é 
significativamente pequena a proporção de profissionais jovens sindicalizados, não chegando a $10 \%$ dos ocupados.

Assim, começam-se a conhecer as condições em relação às oportunidades de trabalho enfrentadas por esses jovens de 16 a 24 anos, sendo um dos fatores explicativos do aumento da posição do jovem no panorama do empreendedorismo do Brasil.

Tabela 2

Taxa de informalidade, sindicalização e contribuição à Previdência Social de jovens de 16 a 24 anos e adultos de 25 anos e mais, no Brasil em 2006

\begin{tabular}{|lcc|}
\hline \multicolumn{1}{c}{ INDICADORES } & $\begin{array}{c}\text { INFORMALIDADE, SINDICALIZAÇÃO E } \\
\text { CONTRIBUIÇÃO À PREVIDÊNCIA SOCIAL } \\
\text { (em \%) }\end{array}$ \\
\cline { 2 - 3 } & $\begin{array}{c}\text { Jovens de } \\
16 \text { a } 24 \text { anos }\end{array}$ & $\begin{array}{c}\text { Adultos de } \\
25 \text { anos ou mais }\end{array}$ \\
\hline Taxa de informalidade & 58,9 & 50,7 \\
Ocupados que não contribuíam para a Previdência Social & 57,7 & 47,8 \\
Ocupados associados a sindicato & 9,3 & 21,6 \\
\hline
\end{tabular}

Fonte: Projeto..., 2008

\subsection{Tendências demográficas da atividade empreendedora no Brasil}

Na busca dos fundamentos socioeconômicos que contribuam para o entendimento da ação empreendedora do jovem no Brasil, os indicadores formação, escolaridade, tipo de atividade do empreendimento e renda do empreendedor serão analisados para entender as transformações recentes na taxa de empreendedorismo no Brasil. Esses indicadores serão utilizados para delinear uma tipologia da ação empreendedora do jovem no Brasil.

Qual a formação do jovem empreendedor brasileiro?

Com relação à formação do jovem empreendedor de 18 a 24 anos, observa-se, na média do período de 2002 a 2008 , que $61 \%$ dos jovens possuem de cinco a 11 anos de escolaridade, $21 \%$ possuem até quatro anos e somente 17\% possuem mais de 11 anos de escolaridade (gráfico 4). 
Gráfico 4

Taxa de empreendedorismo dos jovens de 18 a 24 anos por anos de estudo no Brasil (2002)

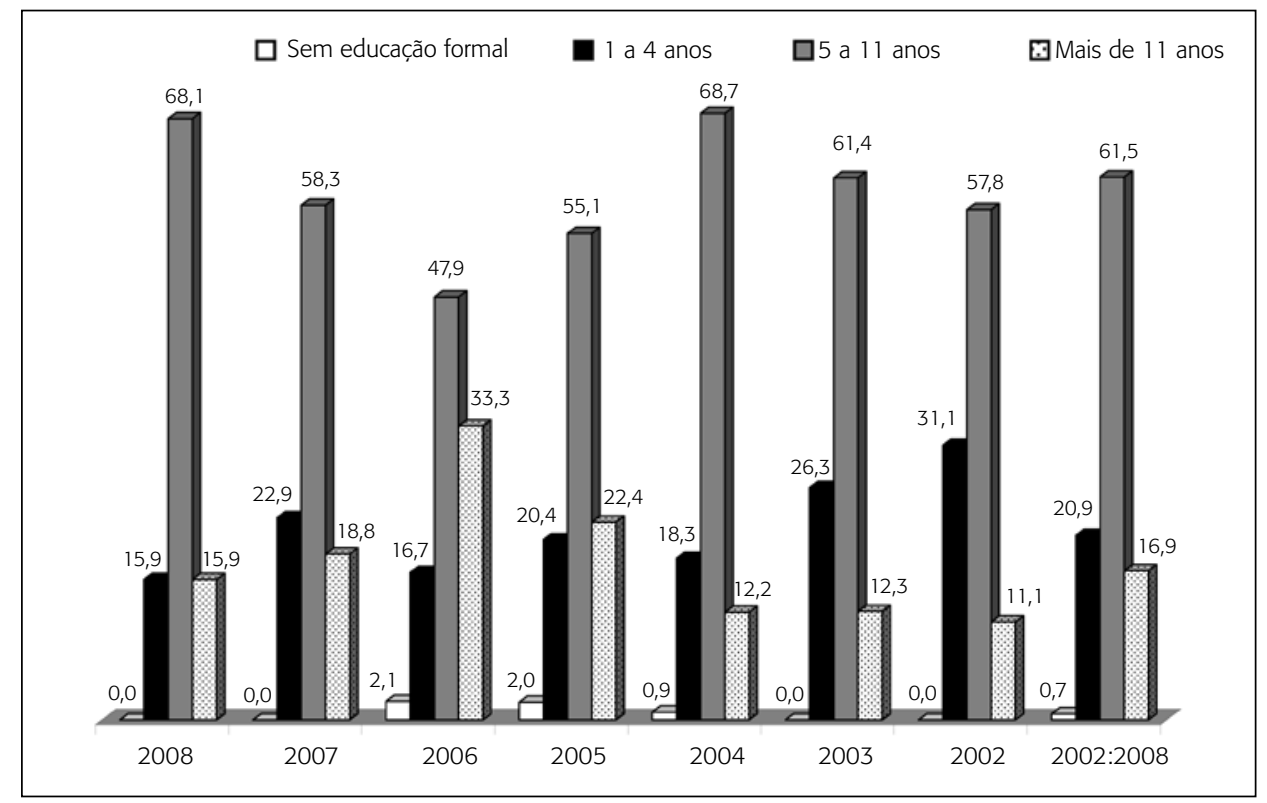

Fonte: Greco e colaboradores (2009).

O baixo nível de escolaridade dos empreendedores jovens tem forte reflexo sobre a possibilidade de sucesso do empreendimento. Essa característica socioeconômica do jovem empreendedor brasileiro limita sua possibilidade de crescimento pessoal e também a de seu negócio. No entanto, embora com grandes oscilações, observa-se uma pequena tendência de melhoria na formação dos jovens empreendedores, especialmente em relação à educação superior.

Mas o que realmente se destaca em relação à formação do jovem empreendedor é a diferença entre a formação do jovem empreendedor por necessidade e por oportunidade.

Em que setor de atividade o jovem concentra seu empreendimento?

As tabelas 3 e 4 mostram a distribuição dos empreendedores jovens de 18 a 24 anos, segundo o setor de atividade nos anos pesquisados. Observa-se que mais de $50 \%$ dos jovens empreendem em serviços orientados a consumidores. Normalmente, esse tipo de serviço é de baixa produtividade e exigência em relação à qualificação e à experiência. Encontram-se classificados nesta atividade serviços pessoais, vendedores ambulantes, serviços de limpeza 
e conservação, entre outros. A proporção dos serviços orientados às empresas, de 2001 a 2008, embora ainda pouco representativa, dobrou no período, o que pode demonstrar uma tendência de o jovem se direcionar, em função da melhoria de formação nos últimos anos, para atividades mais qualificadas.

\section{Gráfico 5}

Escolaridade do jovem empreendedor por oportunidade e por necessidade no Brasil por anos de estudo em 2008

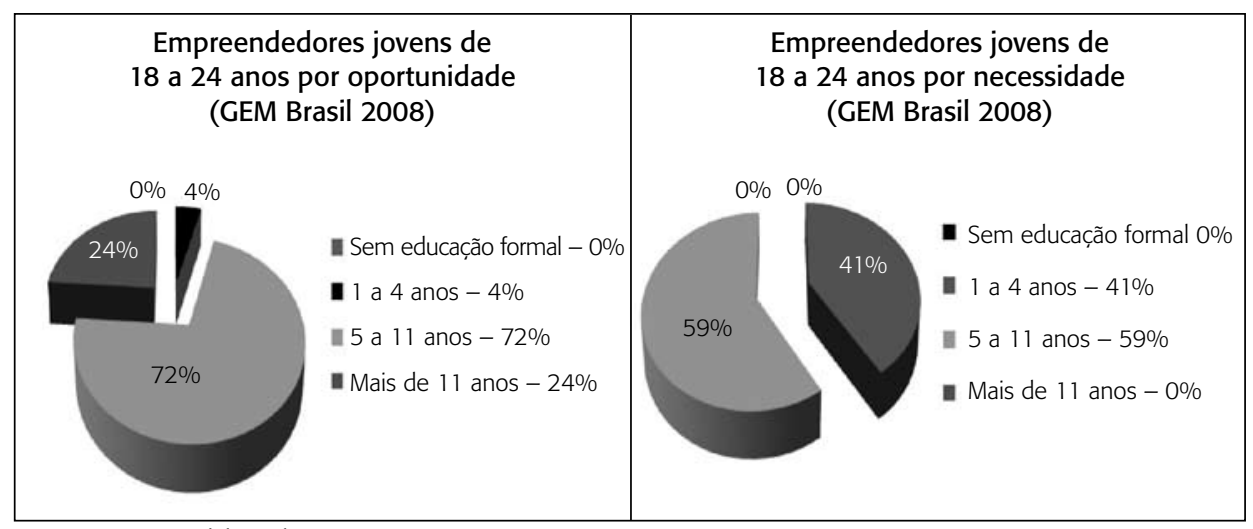

Fonte: Greco e colaboradores (2009).

Tabela 3

Participação dos jovens empreendedores (18 a 24 anos), segundo setor de atividade (Brasil, 2008)

\begin{tabular}{|c|c|c|c|c|c|c|c|c|c|}
\hline \multirow{2}{*}{ SETOR DE ATIVIDADES } & \multicolumn{9}{|c|}{$\begin{array}{c}\text { EMPREENDEDORES JOVENS DE } 18 \text { A } 24 \text { ANOS INICIAIS - } \\
\text { BRASIL - PROPORÇÃO (\%) }\end{array}$} \\
\hline & 2008 & 2007 & 2006 & 2005 & 2004 & 2003 & 2002 & 2001 & 2002:2008 \\
\hline Setor extrativista & 0,0 & 2,1 & 4,8 & 4,1 & 0,9 & 1,8 & 2,2 & $\ldots$ & 1,9 \\
\hline Setor de transformação & 22,7 & 34,0 & 35,7 & 24,5 & 34,8 & 25,5 & 28,9 & $\ldots$ & 29,8 \\
\hline $\begin{array}{l}\text { Serviços orientados às } \\
\text { empresas }\end{array}$ & 22,7 & 12,8 & 16,7 & 16,3 & 7,8 & 10,9 & 11,1 & $\ldots$ & 13,4 \\
\hline $\begin{array}{l}\text { Serviços orientados aos } \\
\text { consumidores }\end{array}$ & 54,5 & 51,1 & 42,9 & 55,1 & 56,5 & 61,8 & 57,8 & $\ldots$ & 54,9 \\
\hline TOTAL & 100,0 & 100,0 & 100,0 & 100,0 & 100,0 & 100,0 & 100,0 & $\ldots$ & 100,0 \\
\hline
\end{tabular}

Fonte: Greco e colaboradores (2009). 
A tabela 4 mostra a distribuição dos empreendimentos dos jovens por setor de atividade segundo a motivação por oportunidade ou necessidade. A motivação é um dos temas mais relevantes para a pesquisa GEM, principalmente para se conhecer melhor a natureza do empreendimento em países em desenvolvimento. A taxa de empreendedorismo por oportunidade reflete o "lado positivo" da atividade empreendedora nos países. Essa porção de empreendedores é aquela que inicia sua atividade para melhorar sua condição de vida ao observar uma oportunidade para empreender. O outro extremo da atividade empreendedora é aquele em que as pessoas empreendem diante de uma necessidade.

Os resultados da pesquisa GEM 2008 mostram claramente que nos serviços orientados aos consumidores o empreendimento é predominantemente motivado pela necessidade, enquanto nos empreendimentos que se orientam para as empresas a motivação predominante é a busca de oportunidade para o desenvolvimento do empreendimento. Esses são, normalmente, empreendimentos nos quais o jovem já possui formação e empreende para atender a uma oportunidade do mercado. Classificam-se nestas atividades empresas de base tecnológica, serviços especializados, tais como consultorias, serviços técnicos, entre outros.

Tabela 4

Empreendedores jovens de 18 a 24 anos por motivação, segundo setor de atividade (Brasil, 2008)

\begin{tabular}{|lccc|}
\hline \multirow{2}{*}{ SETOR DE ATIVIDADES } & \multirow{2}{*}{ TEA TOTAL } & \multicolumn{2}{c|}{ MOTIVAÇÃO } \\
\cline { 3 - 4 } & & Oportunidade & Necessidade \\
\hline Setor extrativista & 0,0 & 0,0 & 0,0 \\
Setor de transformação & 22,7 & 18,2 & 33,3 \\
Serviços orientados às empresas & 22,7 & 29,5 & 4,8 \\
Serviços orientados aos consumidores & 54,5 & 52,3 & 61,9 \\
\hline
\end{tabular}

Fonte: Greco e colaboradores (2009).

Qual a renda do jovem empreendedor brasileiro?

O que realmente preocupa em relação às condições socioeconômicas do jovem empreendedor brasileiro é sua capacidade de sobrevivência. 
Gráfico 6

Renda do jovem empreendedor (18 a 24 anos) por necessidade e por oportunidade no Brasil (2008)

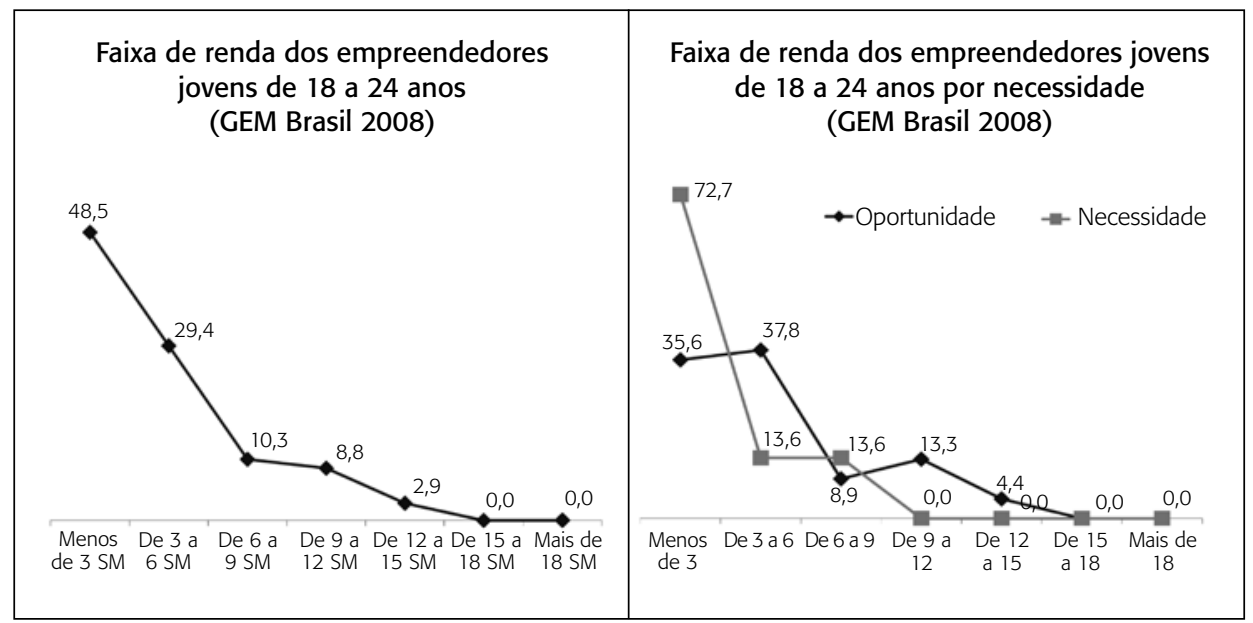

Fonte: Greco e colaboradores (2009).

Os indicadores de renda do jovem empreendedor mostram um cenário desolador e revelam perspectivas pouco animadoras. Quase 50\% dos jovens empreendedores brasileiros estão em uma faixa de renda de até três salários mínimos; se agregarmos a faixa de até 6 salários mínimos, este índice chega a quase $80 \%$. Esse cenário fica ainda mais desolador quando se analisa o nível de renda dos jovens empreendedores por necessidade. Entre eles, 73\% auferem renda menor que três salários mínimos, o que coloca em questão tanto sua capacidade de sobrevivência com a possibilidade de formação desse empreendedor (gráfico 6).

\subsection{A busca de uma tipologia a partir dos indicadores da atividade do jovem empreendedor no Brasil}

O quadro a seguir apresenta uma tipologia que caracteriza a posição do jovem no empreendedorismo brasileiro, segmentado por oportunidade e necessidade. Para cada tipo de empreendedor descrevem-se, na coluna 2, as características observadas de renda, escolaridade e tipo de atividade. 


\section{Quadro 1 \\ Características predominantes dos empreendedores de 18 a 24 anos}

(Brasil, 2008)

\begin{tabular}{|c|c|}
\hline TIPOLOGIA & CARACTERÍSTICAS DOMINANTES \\
\hline $\begin{array}{l}\text { Empreendedor jovem } \\
\text { por necessidade }\end{array}$ & $\begin{array}{l}\text { V } 28 \% \text { dos empreendedores brasileiros } \\
\text { v } 60 \% \text { têm renda de um a três salários mínimos } \\
\text { v } 60 \% \text { têm nível de escolaridade de cinco a } 11 \text { anos } \\
\text { v } 70 \% \text { dos empreendimentos são serviços orientados ao consumidor }\end{array}$ \\
\hline $\begin{array}{l}\text { Empreendedor jovem } \\
\text { por oportunidade }\end{array}$ & $\begin{array}{l}\text { V } 29 \% \text { dos empreendedores brasileiros } \\
\text { V } 36 \% \text { têm renda de um a três salários mínimos } \\
\text { v } 25 \% \text { estão cursando ou já terminaram o nível superior } \\
\text { V } 59 \% \text { concentram-se em atividades de serviços orientados ao consumidor }\end{array}$ \\
\hline
\end{tabular}

Fonte: Greco e colaboradores (2009).

Nota: Quadro adaptado e desenvolvido a partir da tipologia de jovens empreendedores apresentada por Llisterri (2006).

Observa-se que o jovem empreendedor por necessidade, em 2008, representa $28 \%$ dos empreendedores brasileiros (taxa superior à média no período, que é de $20,6 \%$ ), possuindo uma renda concentrada na faixa de um a três salários mínimos (média no período de 60\%) e um nível de escolaridade de cinco a 11 anos (média de 60\% no período), com empreendimentos em atividades de serviços orientados ao consumidor (70\%), seguidas pelo setor de transformação (33\%).

O jovem empreendedor por oportunidade diferencia-se por possuir uma renda maior (36\% até três salários mínimos; $34 \%$ de três a seis salários) e uma escolaridade maior, com $25 \%$ deles cursando ou já tendo terminado o nível superior. Ambos têm uma alta concentração em atividades de serviços orientados aos consumidores e atividades de transformação. Entretanto, os empreendedores por oportunidade iniciam seus negócios com atividades mais especializadas, em função de seu maior nível de qualificação e renda. Os empreendedores por oportunidade têm uma participação maior em serviços orientados à empresa (19\%), uma vez que esse tipo de serviço exige maior nível de qualificação e formação. O jovem universitário, por exemplo, ante a escassez do trabalho formal, abre seu negócio em serviços especializados, tais como contabilidade, apoio jurídico, apoio de informática etc.

Quais os fatores determinantes na mudança demográfica do empreendedor brasileiro? Os indicadores de empreendedorismo dos segmentos analisados neste artigo sugerem que são os jovens entre 16 e 24 anos que por necessidade buscam na atividade empreendedora sua sobrevivência. 
Portanto, como já foi analisado, a crescente participação do jovem empreendedor é uma das condições geradas pela flexibilização do mercado de trabalho e de seus reflexos nas relações sociais.

Não se pode considerar, como visto, o jovem empreendedor como um grupo homogêneo. Pelo menos, identificam-se dois grupos de jovens que desenvolvem atividades empreendedoras. De um lado, os jovens que saem da escola antes de terminar o ensino médio e que começam a trabalhar precocemente, e, de outro, os jovens que terminam cursos superiores e que buscam iniciar sua atividade para obter maior independência ou aumento de renda; são os que poderiam se aproximar dos empreendedores.

A situação da juventude no Brasil serve para contextualizar os dados do GEM 2008 e explicar que o fato de se ter uma elevada taxa de empreendedorismo entre os jovens não se revela necessariamente um fator positivo da posição social, econômica e cultural do jovem no Brasil de hoje. Pelo contrário, esse fato está associado às condições de um trabalho precário e à flexibilização do trabalho.

\subsection{0 jovem empreendedor brasileiro: um debate sobre comportamento e ação empreendedora}

Neste item procura-se diferenciar ação empreendedora de comportamento empreendedor de um jovem que desenvolve uma atividade para melhorar sua condição de vida ao observar uma oportunidade, e de outro jovem que desenvolve uma atividade por necessidade e que se insere na lógica da flexibilização do trabalho precário.

Adota-se aqui a diferenciação realizada por Guerreiro-Ramos (1989) entre comportamento e ação. Para o teórico, a ação é própria de um agente, que delibera, escolhe entre alternativas, constituindo uma forma ética de conduta; sendo o comportamento aquele socialmente condicionado, à mercê de eventos episódicos; motivado por conveniência/necessidade. Para GuerreiroRamos (1989), quando a condição humana é presumida como apenas social, a fluidez da individualidade, característica do ato de se comportar, é inevitável; o sujeito fica à mercê de necessidades e contingências. Talvez a aproximação da conceituação de ação de Hanna Arendt (2001) esclareça um pouco mais o significado de ação. Segundo a autora, seria a única atividade que se exerce diretamente entre os homens sem a mediação das coisas ou da matéria, correspondendo à condição humana da pluralidade. Destaca-se, aqui e além, a questão da pluralidade, que se aproxima da condição de escolha e que pode se aproximar do conceito de empreendedorismo por oportunidade, na medida 
em que entram consciência, escolha, reflexão, proação, e não simplesmente reação. Em contrapartida, entende-se o "comportamento" empreendedor como aquele motivado por necessidade de sobrevivência, sem possibilidade de escolha e condicionado por condições de pobreza, limitantes das possibilidades de um vir a ser digno e humano.

Os dados do GEM 2008, olhados a partir da diferenciação de ação e comportamento, demonstram que uma porcentagem significativa de jovens brasileiros pode ser identificada como desenvolvendo comportamento empreendedor e não ação empreendedora.

$\mathrm{O}$ jovem empreendedor por necessidade que busca no empreender o atendimento das necessidades de geração de renda encontra, frequentemente, uma forte barreira determinada pelo nível de educação e pela falta de experiência em planejamento de negócios. Ele tende a reproduzir o círculo vicioso que resulta na transmissão intergerações da pobreza; em lugar de se constituírem num mecanismo que supere os problemas dos lares de origem, se reproduzem essas mesmas situações. Ou seja, a vulnerabilidade ao fracasso desses jovens pobres diante do mercado de trabalho é maior para aqueles que provêm de lares mais pobres do que para os de maiores rendas. De igual forma, esses jovens tendem a se concentrar na informalidade e em postos sem proteção social, em comparação com aqueles provenientes de lares com maiores rendas. Quando o empreendimento fracassa, afeta a moral e a atitude dos jovens, desenvolvendo-se, em muitos casos, um sentido de culpabilidade ao se assumir como responsável de seu fracasso (Tokman, Corrochano e Gouvêa, 2003).

Por outro lado, para o jovem empreendedor por oportunidade, embora tenha uma condição socioeconômica e educacional melhor (cursou ou já terminou o curso superior), a falta de experiências e de recursos leva a um alto percentual de fracassos que emergem nos primeiros meses de operação.

Ao colocar em discussão a atividade empreendedora - que historicamente tem sido compreendida a partir de uma perspectiva individualizada e subjetiva -, pretendeu-se inseri-la em outra abordagem que compreende a ação empreendedora como resultado de um processo de aprendizagem e condicionada pela configuração de condições sociais, econômicas e culturais singulares.

\section{Políticas públicas: orientações estratégicas para 0 jovem empreendedor}

Sem adequadas condições, oportunidades e coerentes políticas públicas, os jovens estarão cada vez mais vulneráveis. Nesta seção serão destacadas algumas 
orientações estratégicas gerais, seguidas de alguns programas e ações que no Brasil foram implantados.

Considerando a heterogeneidade das características do empreendedor antes delineada, aponta-se, a seguir, para um número de políticas e programas de suporte que, como indica Llisterri e colaboradores (2006), são necessários para o desenvolvimento desse segmento ocupacional. Em relação ao jovem empreendedor por necessidade, sugere o autor, basicamente, programas de motivação, de treinamento e, em alguns casos, de assistência técnica e de microcréditos; enquanto para o jovem empreendedor por oportunidade o adequado seria treinamento de alto nível, tutoria, redes de relacionamento, incubadora e mecanismos de busca de capital. A partir dessas sugestões apontadas, o que podemos constatar de incentivos a esse jovem na realidade brasileira?

Quadro 2

Tipologia e políticas para o jovem empreendedor brasileiro

\begin{tabular}{|c|c|c|c|}
\hline TIPOLOGIA & $\begin{array}{l}\text { CARACTERÍSTICAS } \\
\text { DOMINANTES }\end{array}$ & $\begin{array}{l}\text { POLÍTICAS E INSTRUMENTOS } \\
\text { ADEQUADOS DE APOIO }\end{array}$ & $\begin{array}{c}\text { POLÍTICAS EXISTENTES } \\
\text { NO BRASIL }\end{array}$ \\
\hline $\begin{array}{l}\text { Empreendedor } \\
\text { jovem por } \\
\text { necessidade }\end{array}$ & 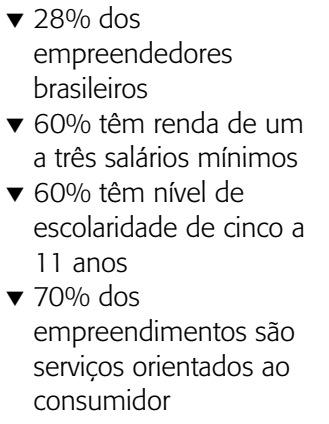 & 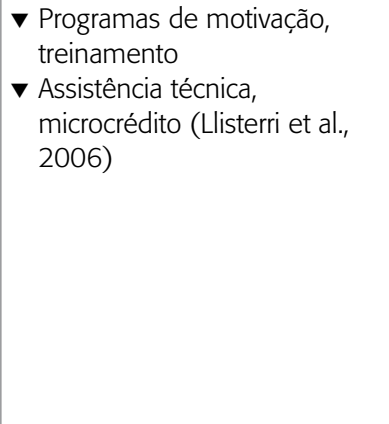 & $\begin{array}{l}\text { Primeiro emprego, Pro } \\
\text { Jovem Trabalhador }\end{array}$ \\
\hline $\begin{array}{l}\text { Empreendedor } \\
\text { jovem por } \\
\text { oportunidade }\end{array}$ & 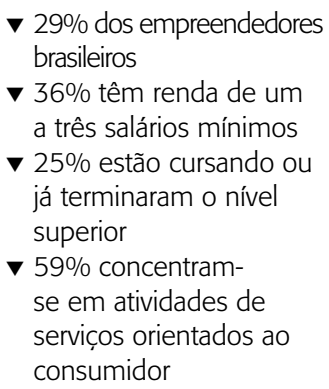 & 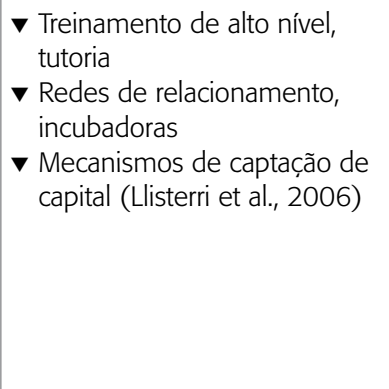 & $\begin{array}{l}\text { Jovem empreendedor } \\
\text { - Sebrae }\end{array}$ \\
\hline
\end{tabular}

Fonte: Greco e colaboradores (2009).

Nota: Quadro adaptado e desenvolvido a partir da tipologia de jovens empreendedores apresentada por Llisterri e colaboradores (2006). 
Do ponto de vista das políticas públicas em geral, Sposito e Carrano (2003) traçam o panorama da realidade brasileira destinada aos jovens nos últimos 10 anos, sinalizando que é a partir de 1990 e no início da década atual que as políticas se voltam para contemplar ações especialmente dirigidas para o jovem, envolvendo parcerias com instituições da sociedade civil e instâncias do Poder Executivo, federal, estadual e municipal. Identificando serem ações voltadas para a perspectiva de reconhecimento de problemas que afetam a juventude em torno do conceito de risco social, respondendo pela criação de programas esportivos, culturais e de trabalho orientados para controle do tempo livre. Acentuam a heterogeneidade e a amplitude dos programas que tratam ao mesmo tempo de crianças, adolescentes e jovens. Ainda segundo esses autores, foram 30 programas/projetos governamentais incidindo com maior ou menor focalização nas faixas etárias comumente consideradas como jovens (adolescentes de 15 a 19 e jovens de 20 a 25 anos) e três ações governamentais de âmbito nacional: Programa Capacitação Solidária; Programa Rede Jovem e Programa Alfabetização Solidária, que surgem por indução do Programa Comunidade Solidária. Do ponto de vista específico das ações voltadas para o trabalho, Llisteri e colaboradores (2006) apontam a existência, no Brasil, apenas do Programa do Primeiro Emprego. Segundo o Ministério do Trabalho, existe também um Programa Pro Jovem Trabalhador voltado para preparar o jovem para o mercado de trabalho e para ocupações alternativas e geradoras de renda.

Quanto ao jovem empreendedor por oportunidade ressalta-se o programa Jovem Empreendedor do Sebrae. Convém destacar que a Lei no 9.394/1996 das Diretrizes e Bases da Educação Nacional (LDB) e o Decreto no 2.208/1997 estabeleceram um novo modelo educacional, focalizado na construção de competências e habilidades e tendo como objetivo o processo de aprendizagem no qual o "aprender a aprender" e o "aprender a fazer" estivessem sempre presentes, com uma lógica de formação de atitudes, condutas e crenças. Com essa abordagem educacional esperava-se contribuir para que os alunos, formados hoje, fossem muito mais autônomos e desembaraçados do que os do passado, ou seja, um novo modelo voltado para a educação empreendedora (Paiva Jr., Leão e Mello, 2003:33). Importante destacar também o Programa de Consórcios Sociais da Juventude, lançado pelo Ministério do Trabalho, que institui um instrumento para consolidação da parceria governo-sociedade a fim de atender o público jovem e garantir a integração das Políticas Públicas de Emprego e Aprendizagem.

Essas novas estratégias de políticas públicas para o jovem brasileiro não se refletem expressivamente nos resultados dos indicadores de atividade, 
tanto do jovem trabalhador quanto nos indicadores do jovem empreendedor. Essas políticas focam o jovem como um grupo homogêneo, não observando as especificidades que foram observadas nesta pesquisa, especialmente em relação aos dois grupos que aparecem na tipologia apresentada neste estudo e que revela as especificidades do jovem empreendedor por oportunidade e por necessidade.

É necessário diferenciar as políticas para o jovem empreendedor por necessidade e por oportunidade, revelados quando se diferencia a ação empreendedora do comportamento empreendedor.

Por um lado, é papel do Estado apoiar e criar as condições socioeconômicas para a potencialização da ação empreendedora do jovem brasileiro que empreende por oportunidade, buscando sua realização pessoal e sua inserção competitiva na economia. Para este grupo de empreendedores, a ação do Estado deve voltar-se para criar as condições para a inovação e o crescimento do empreendimento, através de cursos de gestão, assistência técnica, financiamento, apoio logístico, entre outros. As incubadoras tecnológicas, as incubadoras de empresas e a assistência e o apoio financeiro nos primeiros anos de vida são políticas que têm se revelado transformadoras nos países desenvolvidos.

Por outro, deve, mediante políticas sociais de educação, treinamento e outras formas de inserção social, induzir o jovem que empreende por necessidade a buscar outras formas de inserção no mundo do trabalho, através de instrumentos que transformem seu "comportamento" empreendedor em "ação" de empreender, compreendida como parte de valorização da pessoa e enquanto possibilidade inerente à condição humana, que envolve consciência, imaginação, criatividade, exploração do desconhecido e aprendizagem. Políticas direcionadas para transformar o comportamento empreendedor em ação empreendedora devem voltar-se para o aprendizado, como uma questão de engajamento e de oportunidade para o jovem.

A aprendizagem é elemento fundamental quando se analisa o perfil do empreendedor, principalmente no público jovem. Diversas pesquisas (Ajzen, 1991; Kristiansen e Indarti, 2004) já demonstraram que compreender a intenção empreendedora no jovem demanda identificar as características do entorno onde este jovem vive que afetam favoravelmente a intenção empreendedora. E, neste caso, a aprendizagem se torna elemento indispensável, pois é a partir desse processo experimental que os jovens amadurecem e percebem suas habilidades, conhecimentos e motivação para empreender.

Empreender é essencialmente um processo de aprendizado por meio de práticas que submergem das relações de participação, negociação, experiência 
cumulativa, perturbação e descontinuidade para negociar significados. A atividade de empreender é experimental e fundamentalmente social, realinhando as experiências em relação ao contexto, transformando-o e sendo transformada por ele. Empreender é visto como um processo de aprendizagem que, através da prática, transforma as identidades e as habilidades dos indivíduos para participar do mundo, para mudar tudo ou alguma coisa, para mudar a si próprios. A ação empreendedora constitui trajetória de participação, ou seja, constitui histórias pessoais na relação com a história das comunidades, conectando o passado ao futuro, num processo tanto individual como coletivo.

\section{Considerações finais}

Um dos objetivos deste artigo foi entender a atividade empreendedora do jovem, que historicamente tem sido compreendida a partir de uma perspectiva individualizada e subjetiva, buscando outra abordagem que avalia a ação empreendedora como mediada pelo processo de aprendizagem e imersa em configurações sociais, econômicas e culturais singulares.

A expressiva presença dos jovens no panorama do empreendedorismo no Brasil é determinada pelas condições geradas pela flexibilização do mercado de trabalho e de seus reflexos nas relações sociais, onde o jovem busca nesta atividade sua manutenção e muitas vezes de sua família, e ainda sua formação.

O Brasil está na categoria de países que possuem uma distribuição de renda desigual, no qual grande parcela das famílias possui baixo nível de renda familiar, baixo nível de escolaridade e baixa capacidade de investimento. Além disso, o país possui uma estrutura de produção instável e com atividades econômicas com baixo nível de produtividade e trabalho precário, convivendo com atividades que utilizam tecnologias avançadas e relações de trabalho excessivamente formalizadas. Estas características socioeconômicas impedem que o jovem se dedique especialmente à sua atividade de formação, tendo de buscar no mercado de trabalho alternativas para sua sobrevivência e até de sua família, além de recursos para sua formação.

Ter uma elevada taxa de empreendedorismo entre os jovens não se revelou necessariamente um fator positivo da posição social, econômica e cultural do jovem no Brasil de hoje; pelo contrário, esse empreendedorismo está associado às condições de um trabalho precário e da flexibilização do trabalho.

O cenário apontado acima não é um espaço homogêneo, revelando nuances que se concretizam ora em espaços de realização do jovem na atividade 
empreendedora ora em situações onde o jovem se vê diante de uma situação de frustração em relação a seu projeto de realização. Está se chamando de espaço de realização o que a pesquisa nos revelou de um jovem que, dadas as condições de formação, renda e oportunidade de investimentos, consegue realizar seu projeto de vida - ser empreendedor. Entende-se empreender como uma atividade dirigida por um sujeito, situado e enraizado no social, que pressupõe aprendizagem, escolha, consciência, reflexão e proação para enfrentar um mundo no qual a competitividade baseada nas novas tecnologias de informação e de comunicação direciona e define o caminho do sucesso dos empreendimentos.

O outro jovem - por necessidade —, embora com ações afirmativas de iniciar uma atividade, vive em um espaço no qual são reduzidas as possibilidades de realização no mundo do trabalho, buscando a fuga da exclusão - o "empreender". Que "empreender" é esse? O "empreender" desse jovem é movido pela necessidade de sobrevivência em um mundo altamente competitivo que pressupõe escolaridade, formação e capital para enfrentar um negócio empreendedor, o que, como visto, ele não dispõe, restando-lhe apenas sua vontade e sua determinação para agir e criar as condições de fuga da exclusão. A construção do espaço de realização do jovem passa necessariamente por políticas públicas diferenciadas que atendam à diversidade revelada.

\section{Referências}

AJZEN, I. The theory of planned behavior. Organizational Behavior and Human decision Processes, v. 50, p. 179-211, 1991.

ARENDT, H. Entre o passado e o futuro. 5. ed. São Paulo: Perspectiva, 2001.

CAMARGO, D.; CUNHA, S.K.; BULGACOV, Y.L.M. A psicologia de McClelland e a economia de Schumpeter no campo do empreendedorismo. RDE, Salvador, v. 10, n. 17, jan. 2008.

CARRETEIRO, T.C. A doença como projeto: uma contribuição à análise de formas de afiliações e desafiliações sociais. In: SAWAIA, B. (Org.). As artimanhas da exclusão: análise psicossocial e ética da desigualdade. São Paulo: Vozes, 2001. p. 87-116.

CASTELLS, M. Hacia el Estado red? Globalización económica e instituciones políticas em la era de la información. In: SEMINÁRIO SOCIEDADE E A REFORMA DO ESTADO, Maré. Mimeografado. . A sociedade em rede. São Paulo: Paz e Terra, 1999. 
CATTANI, A.D.; HOLZMANN, L. (Ed.). Trabalho e tecnologia: dicionário crítico. Porto Alegre: Editora da UFRGS, 2006.

CLOTT, Y. A função psicológica do trabalho. Petrópolis: Vozes, 2006.

ENGESTRÖM, Y. New forms of learning in co-configuration work. Journal of Workplace Learning, 2004.

GLOBAL ENTREPRENEURSHIP MONITOR (GEM). Empreendedorismo no Brasil. Relatório de Pesquisa 2008. Curitiba: IBQP, 2009.

GRECO, Simara Maria de Souza Silveira et al. Pesquisa GEM 2008: Global Entrepreneurship Monitor' - empreendedorismo no Brasil: 2008. Curitiba: IBQP; 2009.

GUERREIRO-RAMOS, A. A nova ciência das organizações: uma reconceituação da riqueza das nações. Rio de Janeiro: Fundação Getulio Vargas, 1989.

HOLZMAN, L. A dimensão do trabalho precário no Brasil no início do século XXI. In: PICCININI, V. et al. (Org.). O mosaico do trabalho na sociedade contemporânea: persistências e inovações. Porto Alegre: Editora da UFRGS, 2006.

INSTITUTO BRASILEIRO DE GEOGRAFIA E ESTATÍSTICA (IBGE). O perfil do idoso responsável pelo domicílio. Estudos e Pesquisas Informação Demográfica e Socioeconômica, Rio de Janeiro, n. 9, 2002.

. Perfil da mulher responsável pelo domicílio no Brasil. Estudos e Pesquisas Informação Demográfica e Socioeconômica, Rio de Janeiro, n. 8, 2002.

. Tendências demográficas: uma análise da população com base nos resultados do Censo Demográfico entre 1940-2000. Estudos e Pesquisas Informação Demográfica e Socioeconômica, Rio de Janeiro, n. 20, 2007.

. Pesquisa Nacional de Amostra Domiciliar 2006. Rio de Janeiro: IBGE, 2006. Disponível em: <www.ibge.gov.br/home/estatistica/populacao/trabalhoerendimento/>. Acesso em: 18 nov. 2009.

KOZULIN, A. Instrumentos psicológicos. Barcelona: Paidós, 2000.

KRISTIANSEN, S.; INDARTI, N. Entrepreneurial Intention among indonesian and Norwegian students. Journal of Enterprising Culture, v. 12, n. 1, p. 55-78, 2004.

LEHR, U. A revolução da longevidade: impacto na sociedade, na família e no indivíduo. Estudos Interdisciplinares sobre o Envelhecimento, Porto Alegre, v. 1, p. 7-35, 1999.

LLISTERRI, J.J. et al. Is youth entrepreneurship a necessity or an opportunity? A first exploration of household and new enterprise surveys in Latin America. Washington: Inter-American Development Bank, 2006. 
McCLELLAND, D.C. A sociedade competitiva: realização e progresso social. Rio de Janeiro: Expressão e Cultura, 1972.

PAIVA JÚNIOR, F.G.; LEÃO, A.L.; MELO, S.C. Competências empreendedoras em comportamento de dirigentes de êxitos sociais reconhecidos. In: ENANPAD, 2003, Salvador. Anais... Salvador: Enanpad, 2003.

POCHMANN, M. O mercado de trabalho reproduz a desigualdade. São Paulo: Casa Amarela, ago. 2009. Entrevista concedida à revista Caros Amigos.

PROJETO CEPAL/PNUD/OIT. Emprego, desenvolvimento humano e trabalho decente: a experiência brasileira recente. Brasília: Cepal/Pnud/OIT, 2008.

SPOSITO, M.P.; CARRANO, P.C.R. Juventude e políticas públicas no Brasil. Revista Brasileira de Educação, n. 24, p. 16-39, set./dez. 2003. Disponível em: <www. sebraesp.com.br/noticias/node/6325 >. Acesso em: 10 dez. 2008.

THÉBAUD-MONY, A.; DRUCK, G. Terceirização: a erosão dos direitos dos trabalhadores na França e no Brasil. In: DRUCK, G.; FRANCO, T. (Org.). A perda da razão social do trabalho: terceirização e precarização. São Paulo: Boitempo, 2007. (Coleção Mundo do Trabalho)

TOKMAN, V.E.; CORROCHANO, M.C.; GOUVÊA, J.L. Desemprego juvenil no Cone Sul: uma análise de década. São Paulo: Fundação Friedrich Ebert, 2003.

WAISELFISZ, J. J. Juventude, violência e cidadania: os jovens de Brasília. São Paulo: Cortez, 1998.

WENGLER, E.; LANE, J. Prática, pessoa, mundo social. In: DANIELS, H. (Org.). Uma introdução a Vygotsky. São Paulo: Loyola, 2004. p. 165-173. 